\title{
Removal of the Hypoglycaemic Drug Gliclazide From Aqueous Solutions by Carbon-Based Magnetic Materials
}

Ferda Civan Çavuşoğlu ( $\square$ ferda.cvn@gmail.com )

Beykent University: Beykent Universitesi https://orcid.org/0000-0003-1401-7607

\section{Research Article}

Keywords: Adsorption, gliclazide, magnetic nanoparticles, multiwalled carbon nanotubes, powdered activated carbon

Posted Date: August 30th, 2021

DOI: https://doi.org/10.21203/rs.3.rs-856409/v1

License: (c) (1) This work is licensed under a Creative Commons Attribution 4.0 International License. Read Full License 


\section{REMOVAL OF THE HYPOGLYCAEMIC DRUG GLICLAZIDE FROM AQUEOUS SOLUTIONS BY CARBON-BASED MAGNETIC MATERIALS}

\section{Ferda Civan Çavuşoğlu ${ }^{1 *}$}

1 Beykent University, Faculty of Engineering and Architecture, Chemical Engineering Department, Sarıer, İstanbul, 34396, Turkey.

*Corresponding Author: e-mail: ferda.cvn@gmail.com , ferdacavusoglu@ beykent.edu.tr Tel: +90-212-4441997 Fax: +90-212-867-5066

\section{ABSTRACT}

Adsorption of gliclazide from aqueous solutions with carbon-based adsorbents is the aim of this study. For this purpose, magnetic, versatile, and inexpensive magnetic activated carbon (MAC) and magnetic multi-walled carbon nanotube (MMWCNT) adsorbents have been developed. MAC and MMWCNT characterization were analyzed using Fourier-transform infrared spectroscopy (FTIR), X-ray diffraction (XRD) and Thermogravimetric analysis (TGA) techniques. In order to find the optimum conditions in batch adsorption experiments, the effects of parameters such as adsorbent dose, gliclazide solution $\mathrm{pH}$, contact time, temperature and presence of foreign ions were investigated. Parameters were calculated for adsorption isotherms using Langmuir and Freundlich models. The adsorption studies of MAC and MMWCNT materials with gliclazide were in accordance with the nonlinear Langmuir and Freundlich isotherm models for all temperatures $(298,308,318 \mathrm{~K})$. The correlation coefficients of the Langmuir isotherm model are slightly higher than the Freundlich model. MAC adsorbent has maximum monolayer adsorption capacity at $\mathrm{T}=298 \mathrm{~K}\left(\mathrm{q}_{\max }=101.66 \mathrm{mg} / \mathrm{g}, \mathrm{R}^{2}=0.88\right)$ while MMWCNT has maximum monolayer adsorption capacity at $\mathrm{T}=308 \mathrm{~K}\left(\mathrm{q}_{\max }=71.59 \mathrm{mg} / \mathrm{g}\right.$, $\left.\mathrm{R}^{2}=0.90\right)$. For MAC and MMWCNT - Gliclazide adsorption systems, pseudo-first and secondorder kinetic models were examined and found to be more appropriate to the pseudo-secondorder kinetic model. The results showed that the MAC and MMWCNT could be could be promising adsorbents for gliclazide removal.

Keywords: Adsorption, gliclazide, magnetic nanoparticles, multiwalled carbon nanotubes, powdered activated carbon. 


\section{INTRODUCTION}

In recent years, the use of personal care products (PPCPs) such as medical drugs and cosmetics has been increasing rapidly with the improvement in people's living standards (Zhu et al., 2017). Such substances that can be detected in water have been identified as micropollutants found in wastewater streams and groundwater around the pharmaceutical industry. These compounds, which are the cause of many unknown diseases, pose great risks to water and humans (Balasubramani et al., 2020; Alnajjar et al., 2019; Niaei et al., 2020).

The fact that the amount of daily use of such pollutants worldwide is very high is a big problem. Diabetes has become a huge problem globally. According to the 2017 report of the International Diabetes Federation (IDF), diabetes is a worldwide epidemic in which 415 million adults lived with this disease in 2015, and it is estimated that this number will reach 629 million by 2045 . (IDF, 2017). Pharmaceuticals used to treat these diseases include substances such as sulfonylureas (gliclazide, glibenclamide, glimepiride) or biguanidine (metformin) (Mrozik and Stefanska, 2014).

Gliclazide is used to treat patients with non-insulin dependent diabetes mellitus (Type II diabetes). It is a second generation sulfonylurea oral hypoglycemic agent (Al Salami et al., 2008; Palmer and Brogden, 1993). Because large amounts of anti-diabetic drugs are used, these pharmaceuticals can accumulate over time and cause environmental problems (Mrozik and Stefanska, 2014). Therefore, with the aim of effectively eliminating this type of contamination, researchers began looking for quick and simple methods of treating contaminated water (Zhu et al., 2017).

Some reported methods for removing micro-pollutants from contaminated water such as adsorption, photocatalytic degradation, catalytic ozonation, reverse osmosis, membrane separation, solvent extraction, ion exchange, electro-fenton process, phytoremediation, etc (Balasubramani, 2020; Niaei and Rostamizadeh, 2020). Most of these methods require high operating costs to remove contaminants (Niaei and Rostamizadeh, 2020). Of the aforementioned methods, adsorption has proven to be the most functional technique for remediation or treatment of a large number of pollutants due to its low cost, accessibility, excellent performance and environmentally friendly nature (Alnajjar et al., 2019; Zhu et al., 2017). The use of various adsorbents for the removal of drug molecules has been extensively studied (Hoseininezhad et al., 2017). In recent years, various materials have been widely 
applied to eliminate various contaminants such as activated carbon, biochar, ion exchange resin, carbon nanotubes, chitosan, and organic resin (Zhu et al., 2017).

Carbon-based materials are used for different pharmaceutical adsorption studies such as tetracycline, sulfamethoxazole, ciprofloxacin, metformin, aspirin, acetaminophen and caffeine (Zhu et al., 2017). Carbon-based materials such as MWCNT have a very wide surface area and superior pore volume for adsorption systems (Çavuşoğlu et al., 2021). At the same time, carbon nanotubes have perfect conductivity or semiconductivity, high thermality, chemical stability and tensile strength (Hoseininezhad et al., 2017).

Nanomaterials with magnetic properties have found use in many applications such as magnetic separation (Zhu et al., 2017). These magnetically modified materials are highly effective adsorbents, because such components can make easy separation of materials from one another and provide ease of processing (Çavuşoğlu et. al, 2021).

Some researchers have studied the removal of various drugs using multi-walled carbon nanotubes (MWCNTs). Lio et al. performed adsorption of resorcinol on intact MWCNTs and $\mathrm{HNO}_{3}$ treated MWCNTs (Liao et al., 2008). Zhao et al. examined the adsorption mechanism of sulfonamides and non-antibiotic pharmaceuticals using MWCNTs (Zhao et al., 2016). Oleszczuk et al. performed removal of oxytetracycline and carbamazepine by MWCNTs (Oleszczuk et al., 2009). There are few studies on the removal of gliclazide in the literature. Mrozik and Stefanska investigated the adsorption and biodegradation of antidiabetic drugs such as gliclazide, glibenclamide, glimepiride, metformin in soil (Mrozik and Stefanska, 2014). Radi et al. removed the hypoglycemic drug gliclazide using electrochemical oxidation method (Radi et al., 1999). There are also many adsorption studies using magnetic materials as adsorbent. Çavuşoğlu et al. prepared magnetic carbon composites for removal of antidiabetic agent metformin hydrochloride (Çavuşoğlu et. al, 2021). Zhou et al. used magnetic dendritic materials for the adsorption of dyes and drugs (Zhou et al., 2010). Bayazit preapared magnetic MWCNTs for methyl orange removal from aqueous solutions (Bayazit, 2014). Huo et al. preapared core/shell nanoadsorbent based on $\mathrm{Fe}_{3} \mathrm{O}_{4}$ magnetic nanoparticles for adsorption of anionic dyes (Huo et al., 2018). Fan et al. performed adsorption of heavy metal ions by magnetic chitosan beads (Fan et al., 2018). Baghdadi et al. synthesized magnetic activated carbon for adsorption of carbamazepine from urban wastewater (Baghdadi et al., 2016).

In this work, magnetically enhanced MAC and MMWCNT adsorbents were used to remove gliclazide contaminants from aqueous solutions. Various parameters affecting the adsorption 
process were investigated. For this purpose, the effects of parameters such as adsorbent dose, $\mathrm{pH}$ of gliclazide solution, contact time, temperature and presence of foreign ions $(\mathrm{NaCl})$ were examined. As a result, isotherm models were created by using adsorbate solutions at different temperatures and concentrations, and the kinetics of the adsorption process were examined with the data obtained at different times.

\section{EXPERIMENTAL SECTION}

\subsection{Chemicals}

Gliclazide (purity>99\%) was supplied by Ali Raif Pharmaceutical Industry Co. (Turkey). The physical properties of gliclazide are presented in Table 1. Activated carbon (AC) was purchased from Merck Co. MWCNT (purity $>98 \%$, length: 1-2 $\mu \mathrm{m}$, outer diameter: 10-20 nm) was purchased from Shenzhen NanoTech. Port. Co. (China). $\mathrm{FeCl}_{3} \cdot 6 \mathrm{H}_{2} \mathrm{O}, \mathrm{Fe}\left(\mathrm{SO}_{4}\right) \cdot 7 \mathrm{H}_{2} \mathrm{O}, \mathrm{HCl}$ (36.5\%), $\mathrm{NaOH}, \mathrm{NaCl}, \mathrm{CH}_{3} \mathrm{OH}$ and $\mathrm{NH}_{4} \mathrm{OH}$ solution (25\%) were received from Merck Co. High purity water from a Millipore Direct-Q3 water treatment system was used in the experiments.

Table 1: Physical properties of gliclazide

\begin{tabular}{ccccc}
\hline Name & Chemical structure & $\begin{array}{c}\text { Molecular } \\
\text { formula }\end{array}$ & $\mathbf{M}_{\mathbf{w}}(\mathbf{g} / \mathbf{m o l})$ & $\lambda \mathbf{m a x}(\mathbf{n m})$ \\
\hline Gliclazide & & & \\
\hline
\end{tabular}

\subsection{Synthesis of Carbon Based Magnetic Materials}

Two different carbon-based materials were used in this study, namely AC and MWCNT. To eliminate amorphous carbon remnants, AC and MWCNT were processed in a ash furnace at $350^{\circ} \mathrm{C}$ for 30 minutes. Subsequently, the materials were oxidized with concentrated $\mathrm{HNO}_{3}$ solution for 100 minutes under ultrasonication. After the ultrasonication process was completed, AC and MWCNT particles were washed with distilled water until the solution $\mathrm{pH}$ reached 7. As a final treatment, the neutralized carbons were dried in a vacuum oven at $60^{\circ} \mathrm{C}$.

Magnetic activated carbon (MAC) and magnetic MWCNT (MMWCNT) materials were magnetized using the co-precipitation technique. In this method, carbon materials are magnetized with Fe (II) and Fe (III) ions. The ratio of "Carbon material: Fe (II) + Fe (III)" was 
applied as "1: 4". Fe (II) and Fe (III) ions were dissolved in distilled water and mixed separately. Mixtures prepared by adding carbon material were kept under ultrasonic bath. The $8 \mathrm{M} \mathrm{NH}_{4} \mathrm{OH}$ solution was slowly added dropwise to the mixtures, reaching the $\mathrm{pH}$ of the solution to 11-12. The resulting precipitates were washed at least 5-6 times using distilled water followed by ethanol and dried in a vacuum oven at $60^{\circ} \mathrm{C}$.

\subsection{Characterization of Synthesized Magnetic Materials}

In the first stage of characterization, FTIR analyzes were used to determine the structural properties of magnetic materials. Analyses were carried out using the Bruker Alpha brand device and the $\mathrm{KBr}$ method. XRD analyses were performed at room temperature using Rigaku D/Max-2200 diffractometer brand device ( $\mathrm{Cu} \mathrm{K} \alpha$ radiation, $\lambda=0.15418 \mathrm{~nm}$ ). The intensities of the samples were measured at a scanning rate of $2^{\circ} / \mathrm{min}$ between $20^{\circ}$ and $60^{\circ}$, with a range of 20. TGA analyzes were performed to determine the thermal properties. Analyses were carried out by heating the samples from room temperature to $1000^{\circ} \mathrm{C}$ at a rate of $10^{\circ} \mathrm{C} / \mathrm{min}$ with $5-10$ mg of materials and Hitachi STA-7200 simultaneous thermogravimetric analyzer device under nitrogen $(200 \mathrm{~mL} / \mathrm{min})$.

\subsection{Batch Gliclazide Adsorption Tests}

Adsorption experiments were carried out as a batch process using $100 \mathrm{~mL}$ flasks and $10 \mathrm{~mL}$ adsorbate solution. These flasks were kept in a temperature-controlled orbital shaker for certain equilibration times under constant shaking at $120 \mathrm{rpm}$. The adsorbate stock solution was prepared by dissolving gliclazide in distilled water with some methanol at a concentration of $10 \mathrm{ppm}$. In order to determine the optimal dose of adsorbents with the first parameter effect, different amounts of adsorbents $(0.1,0.25,0.5,0.75$ and $1 \mathrm{~g} / \mathrm{L})$ and gliclazide stock solution were left to shake. Based on preliminary experiments, the parameters were determined as reaction time 120 minutes, temperature $298 \mathrm{~K}$, solution normal $\mathrm{pH}$ value (5.86). After determining the optimal dose, the times to equilibrium of the adsorption for both adsorbents were determined by experiments performed at certain time intervals $(1,5,10,15,30,45,60$, 90, 120, 180 and 240 minutes). Pseudo-first-order (PFO) and pseudo-second-order (PSO) kinetic models were modeled using experimental data from kinetic studies. The effect of the initial gliclazide concentration $(2-10 \mathrm{mg} / \mathrm{L})$ was determined at normal solution $\mathrm{pH}$ using the optimal adsorbent dose and equilibration time. These adsorption tests were carried out at three different temperatures $(298,308$ and $318 \mathrm{~K})$. Model parameters were determined by using the data of experimental sets and Langmuir and Freundlich isotherm models. Finally, the effects of 
different solution $\mathrm{pH}(3,7,9$ and 11) and presence of foreign ion $(\mathrm{NaCl}$ : $0.005,0.01,0.05$ and $0.1 \mathrm{~mol} / \mathrm{L}$ ) on the adsorption capacity were investigated using the optimal adsorbent dose, equilibrium time and $10 \mathrm{mg} / \mathrm{L}$ gliclazide solution. The $\mathrm{pH}$ values of the stock solution were adjusted using $0.1 \mathrm{M} \mathrm{HCl}$ and $0.1 \mathrm{M} \mathrm{NaOH}$ solutions.

After the flasks were kept at the specified time and temperature, the adsorbents were separated with the help of magnets. Adsorbates (gliclazide) concentrations remaining from adsorption were analyzed using UV-Vis spectrophotometer (Jasco V-730) at $227 \mathrm{~nm}$, the maximum absorbance wavelength of gliclazide molecule.

\section{RESULT AND DISCUSSIONS}

\subsection{Characterization Results of Magnetic Materials}

\section{Characterizations of Magnetic Materials}

The structural properties of MAC and MMWCNT, which are the synthesized adsorbents, were characterized by using FTIR, XRD and TGA methods.

FTIR spectra of MAC (1a) and MMWCNT (1b) obtained before and after gliclazide adsorption are shown in Figure 1. FTIR spectra were measured in the range of $400-4000 \mathrm{~cm}^{-1}$. When the spectrum is examined, it is seen that there are similar peaks for both adsorbent before and after adsorption. Fe-O vibrations were seen at $584 \mathrm{~cm}^{-1}$ and $447 \mathrm{~cm}^{-1}$ in MAC, and at $576 \mathrm{~cm}^{-1}$ and $443 \mathrm{~cm}^{-1}$ in MMWCNT. These peaks indicate that a band of approximately 583 and $456 \mathrm{~cm}^{-1}$ is observed in the tetrahedral site $\left(\mathrm{Fe}_{\text {tetra }} \leftrightarrow \mathrm{O}\right)$ and octahedral site $\left(\mathrm{Fe}_{\text {octa }} \leftrightarrow \mathrm{O}\right)$, which is attributed to the intrinsic stress vibrations of the metal (Lei et al., 2017). Carbon materials have similar results for MAC and MMWCNT nanoparticles, such as the peak at $3441-3446 \mathrm{~cm}^{-1}$ is indicative of $\mathrm{O}-\mathrm{H}$ stretching. At the same time, a broad characteristic band of about $3460 \mathrm{~cm}^{-1}$ indicates the stretching modes of $\mathrm{H}_{2} \mathrm{O}$ molecules or - $\mathrm{OH}$ groups on the surface of magnetite particles (Lei et al., 2017). O-H bending peaks are seen at $1380 \mathrm{~cm}^{-1}$ for MAC and $1378 \mathrm{~cm}^{-1}$ for MMWCNT (Çavuşoğlu et al., 2021). On the other hand, peaks are seen at 1055 and 1043 $\mathrm{cm}^{-1}$, which peaks at around $1100 \mathrm{~cm}^{-1}$ corresponding to the bond stretching vibration of $\mathrm{C}-\mathrm{O}$ (Lei et al., 2017). The peaks observed at $1637-1640 \mathrm{~cm}^{-1}$ can be related with $\mathrm{C}=\mathrm{C}$ vibrations (Liu et al., 2020). C-H peaks occur at around $2903 \mathrm{~cm}^{-1}$ for MAC and $2922 \mathrm{~cm}^{-1}$ for MMWCNT. These peaks indicate the bond stretching vibration of C-H (Liu et al., 2020). As can be seen, FTIR results are compatible with the literature. 

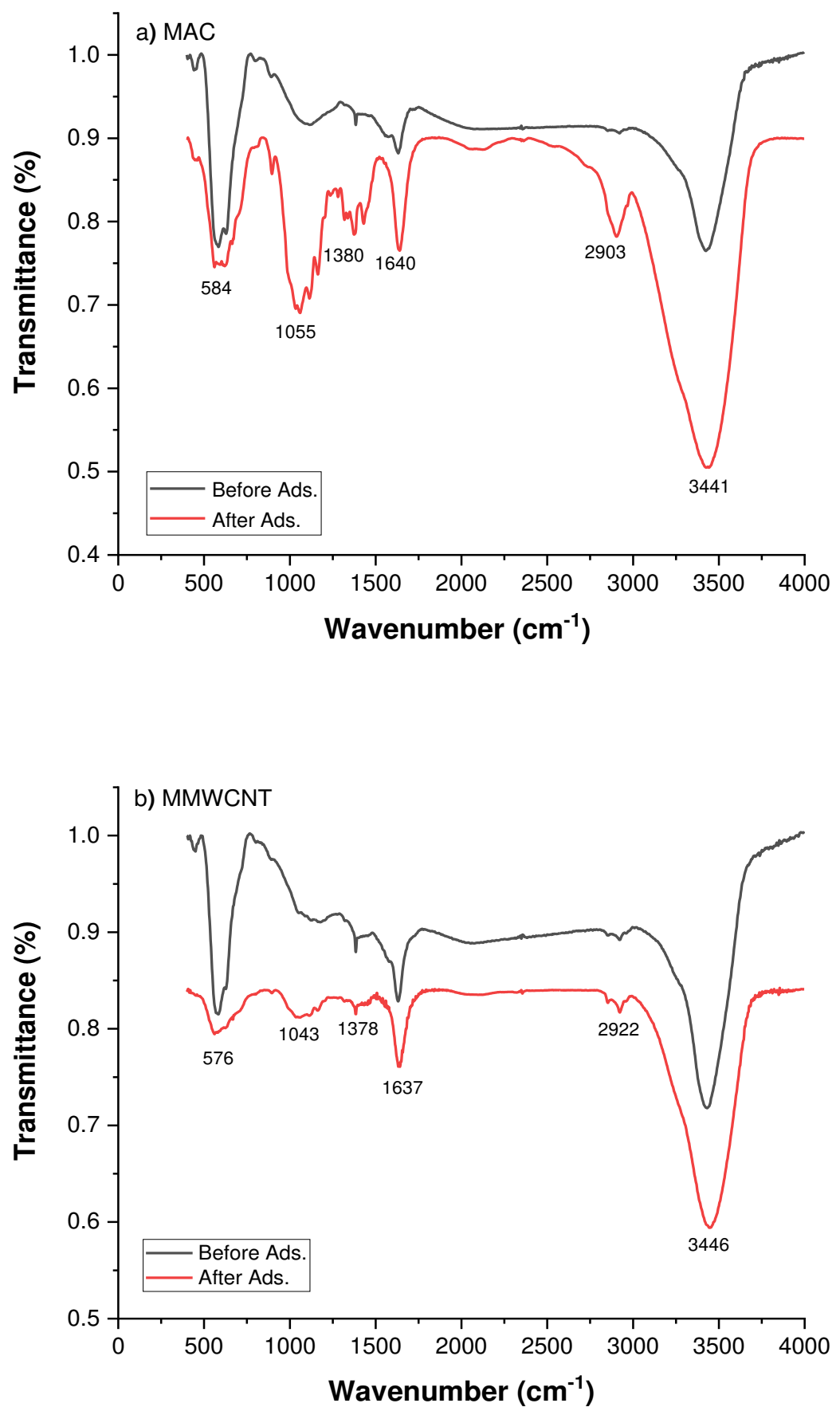

193 Figure 1: FTIR spectrum before and after gliclazide adsorption of MAC (a) and MMWCNT 194 (b)

195 XRD patterns for AC, MAC (2a), MMWCNT (2b) and $\mathrm{Fe}_{3} \mathrm{O}_{4}$ nanoparticles are shown in the 196 Figure 2. All adsorbent materials were compared with those of bare- $\mathrm{Fe}_{3} \mathrm{O}_{4}$. In the XRD model 197 of MAC and MMWCNT, six characteristic peaks of the magnetite spinel structure $\left(\mathrm{Fe}_{3} \mathrm{O}_{4}\right)$ at $19830.16^{\circ}, 35.62^{\circ}, 43.30^{\circ}, 53.72^{\circ}, 57.14^{\circ}$, and $62.82^{\circ}$ were observed to match up to crystal planes 199 220, 311, 400, 422, 511 and 440, respectively. (Danalıoğlu et al., 2017; Habibi, 2014). 
200 MMWCNT nanoparticles present specific peaks at $25.91^{\circ}$ (Shanmugharaj et al., 2007). 201 Therefore, XRD results of MAC and MMWCNT nanoparticles are compatible with the 202 literature.
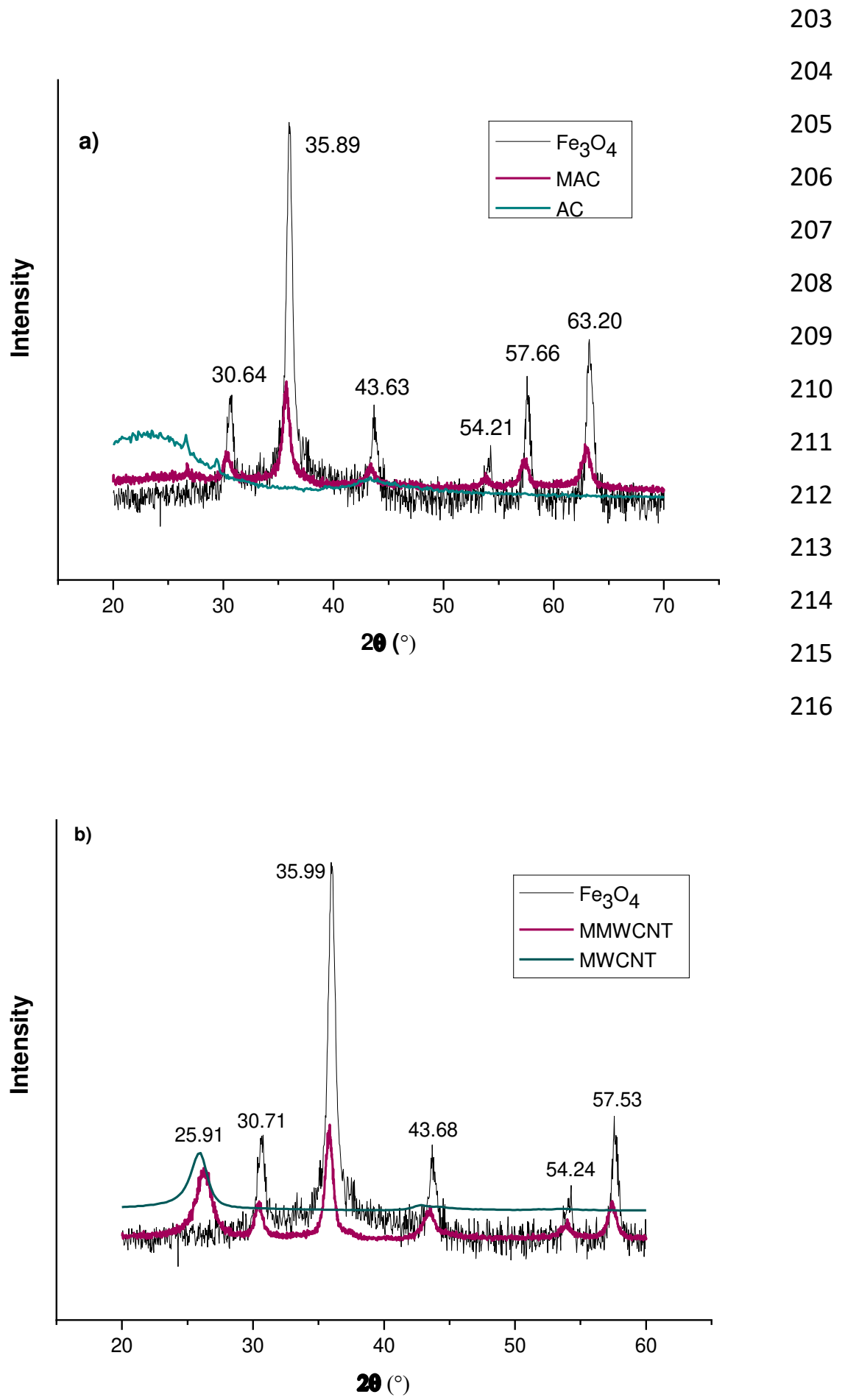

218 Figure 2: XRD of raw $\mathrm{Fe}_{3} \mathrm{O}_{4}, \mathrm{AC}$ and MAC (a) raw $\mathrm{Fe}_{3} \mathrm{O}_{4}, \mathrm{MWCNTP}$ and MMWCNT (b) 
220 TGA and DTA graphics of MAC (a) and MMWCNT (b) are shown in Figure 3. As can be seen,

221 MAC and MMWCNT show similar thermal behavior. The average magnetite content in MAC

222 adsorbent is $66.7 \%$, while it is $72.1 \%$ in MMWCNT. As seen in Figure 3b, the decomposition

223 temperatures of MAC and MMWCNT determined are $868^{\circ} \mathrm{C}$ and $911^{\circ} \mathrm{C}$, respectively.

224 According to the final thermal oxidative decomposition temperatures, it was seen that

225 MMWCNT had higher thermal resistance than MAC adsorbent. The reason for this is the

226 amount of carbon in their content.

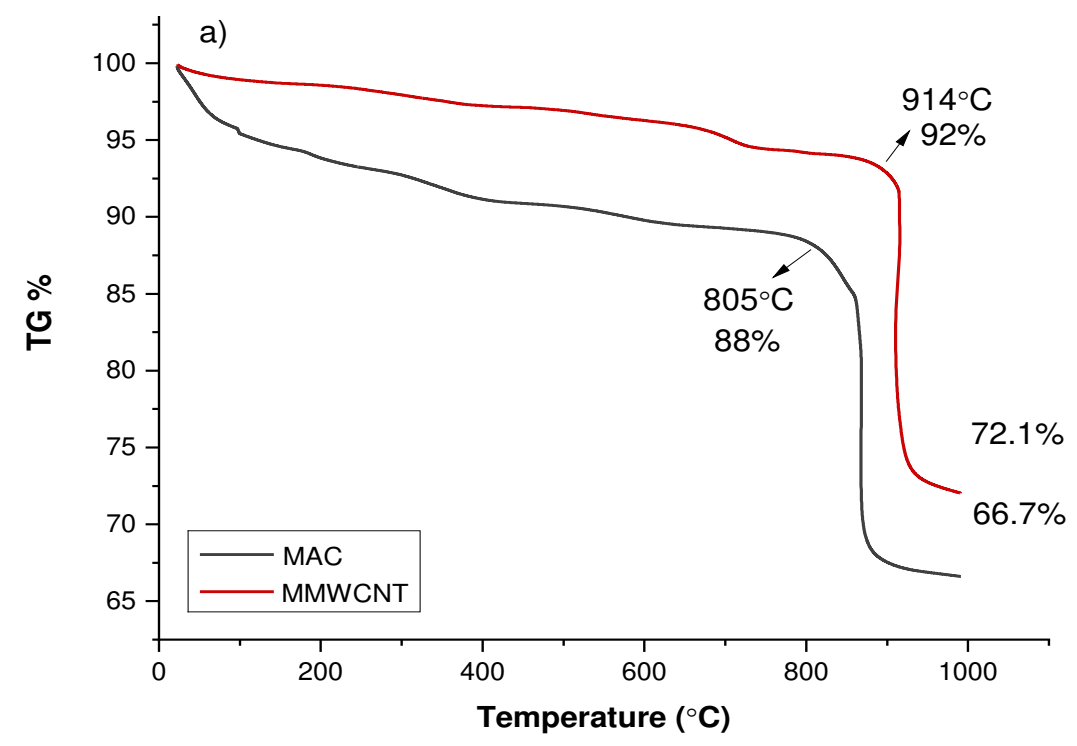

227

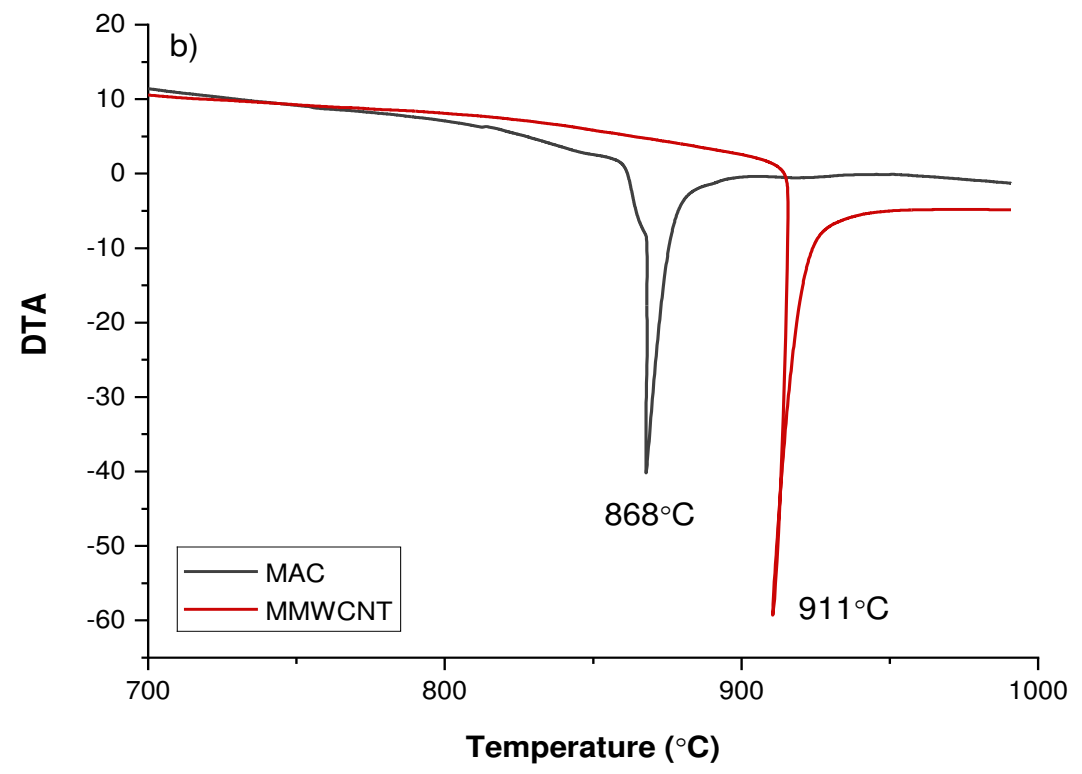


In adsorption studies, gliclazide concentrations were measured at $227 \mathrm{~nm}$ by UV-Vis spectrophotometer. Figure 4 (a) shows the effect of the adsorbent dose in the range of $0.1-1 \mathrm{~g}$ /L on the adsorption capacity of gliclazide.

$$
q e=\frac{(\mathrm{Co}-\mathrm{Ce}) \cdot \mathrm{V}}{\mathrm{m}}
$$

The adsorption capacity of the adsorbents (qe, mg/g) were calculated using Eq. (1). Where Co $(\mathrm{mg} / \mathrm{L})$ is the initial concentration of gliclazide, $\mathrm{Ce}(\mathrm{mg} / \mathrm{L})$ is the equilibrium concentration of gliclazide and $\mathrm{V}(\mathrm{L})$ is the volume of the solution. $\mathrm{m}(\mathrm{g})$ is the amount of the adsorbent.

At the same time, adsorption efficiencies are calculated by Eq. (2) and its graph is given in Figure 4 (b).

$$
\% \text { Eff. }=\frac{(\mathrm{Co}-\mathrm{Ce})}{\text { Co }} \times 100
$$

The effect of adsorbent dose on adsorption capacity (a) and percent removal of gliclazide (b) are shown in Figure 4. The qe values for MAC ranged from $82.3 \mathrm{mg} / \mathrm{g}$ to $12.02 \mathrm{mg} / \mathrm{g}$, while the MMWCNT ranged from $42.59 \mathrm{mg} / \mathrm{g}$ to $9.81 \mathrm{mg} / \mathrm{g}$. When the results were examined, as the amount of adsorbent increased, the adsorption capacity decreased. This result is due to the reduction of the total surface area per active adsorption site and/or due to the agglomeration of the nano-adsorbent.

The adsorption efficiency for MAC reaches $97.83 \%$ while for MMWCNT it is $75.63 \%$. With a small increase in adsorbent dose, more adsorption surface area regions are available for the drug to be adsorbed. Further increase of the adsorbent does not change the result much because of the absence of adsorbate. In subsequent experimental studies, the adsorbent dose was chosen as $1 \mathrm{mg}$. The results are in agreement with the literature. 

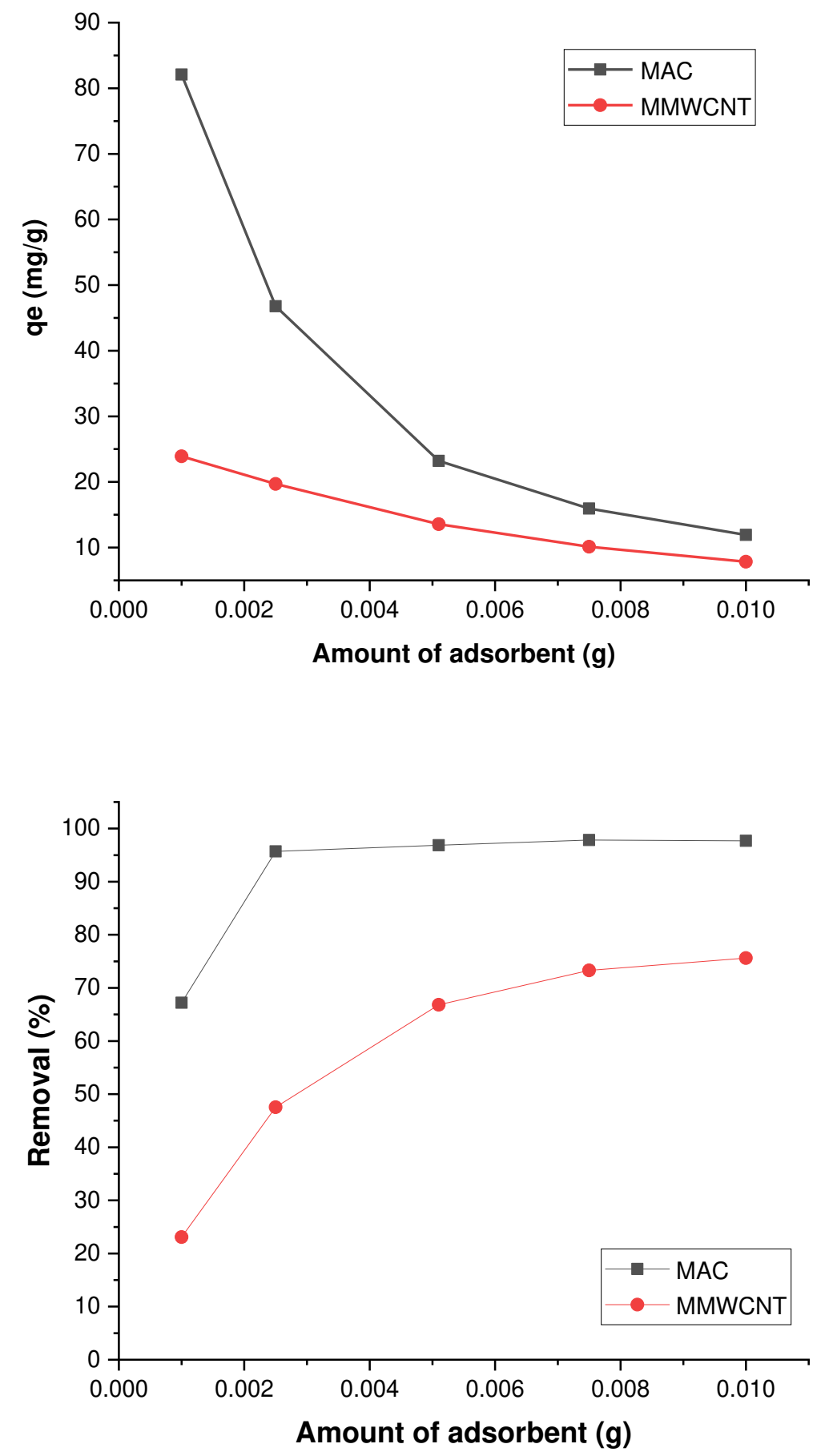

Figure 4: Effect of the adsorbent amount on adsorption capacity (a) and adsorption efficiency (b). Operating conditions: $\mathrm{pH}=5.86, \mathrm{~T}=298 \mathrm{~K}, \mathrm{t}=120 \mathrm{~min}$ and $\mathrm{Co}=10 \mathrm{mg} / \mathrm{L}$. kinetic model parameters were calculated using Eq. (3) (Lagergren, 1898) and Eq. (4) (Ho and McKay, 1999), respectively. Where, $\mathrm{q}_{\mathrm{t}}(\mathrm{mg} / \mathrm{g})$ is the adsorption capacity at $\mathrm{t}$ time, $\mathrm{k}_{1}\left(\mathrm{~min}^{-1}\right)$ is PFO rate constant, $\mathrm{k}_{2}(\mathrm{~g} / \mathrm{mg} \cdot \mathrm{min})$ is PSO rate constant and $\mathrm{t}(\mathrm{min})$ is the contact time. 


$$
q_{t}=q_{e} x\left(1-e^{-k_{1} x t}\right)
$$

$$
q_{t}=\frac{t_{2} q_{e}^{2} t}{1+k_{2} q_{e} t}
$$

268

269 Kinetic curves for MAC and MMWCNT generated using experimental data and kinetic models are shown in Figure 5 and model parameters in Table 2. In order to determine the equilibration times for both adsorbents, experiments were carried out at different time intervals using kinetic models. Equilibrium times of MAC and MMWCNT were determined as 120 and 180 minutes, respectively.

Table 2: Pseudo first order and pseudo second order kinetic model parameters for MAC and

\begin{tabular}{lcccccr}
\hline \multirow{2}{*}{ Gliclazide Adsorption } & \multicolumn{2}{c}{$\begin{array}{c}\text { Pseudo first order kinetic } \\
\text { model }\end{array}$} & \multicolumn{3}{c}{ Pseudo second order kinetic } \\
& \multicolumn{3}{c}{ model } \\
\cline { 2 - 7 } & $\mathbf{q}_{\mathrm{e}}(\mathrm{mg} / \mathrm{g})$ & $\mathbf{k}_{\mathbf{1}}\left(\mathrm{min}^{-1}\right)$ & $\mathbf{R}^{\mathbf{2}}$ & $\mathbf{q}_{\mathrm{e}}(\mathrm{mg} / \mathrm{g})$ & $\mathbf{k}_{\mathbf{2}}(\mathrm{g} / \mathrm{mg} \cdot \mathrm{min})$ & $\mathbf{R}^{\mathbf{2}}$ \\
\hline \multirow{2}{*}{ MAC } & 63.66 & 0.066 & 0.89 & 71.45 & 0.001 & 0.93 \\
\hline \multirow{2}{*}{ MMWCNT } & 17.19 & 0.060 & 0.80 & 18.95 & 0.005 & 0.81 \\
\hline
\end{tabular}

The parameters of the kinetic models showed that the adsorption process for both adsorbents was compatible with the PFO and PSO kinetic models $\left(\mathrm{R}^{2}>0.80\right)$. When the results were compared with the experimental data and the correlation coefficients were examined, it was seen that the PSO kinetic model was more compatible with a small difference. The experimental data of the adsorption capacity and the results of the model parameters were found to be compatible (MAC: $\mathrm{q}_{\mathrm{t}}=71.45 \mathrm{mg} / \mathrm{g}, \mathrm{q}_{\mathrm{e}}=77.35 \mathrm{mg} / \mathrm{g} ;$ MWCNT: $\mathrm{q}_{\mathrm{t}}=18.95 \mathrm{mg} / \mathrm{g}, \mathrm{q}_{\mathrm{e}}=17.64$ $\mathrm{mg} / \mathrm{g})$. 

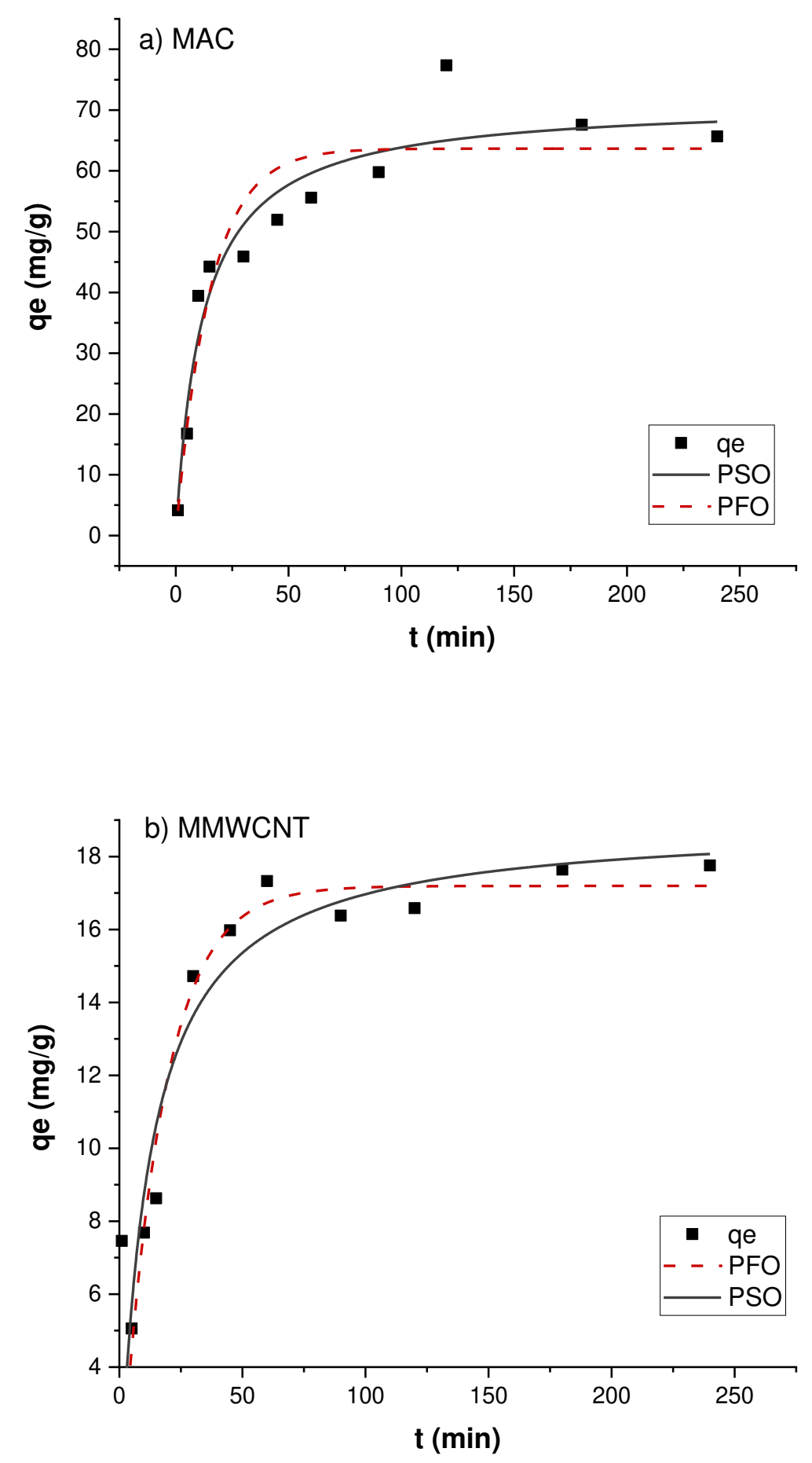

287 Figure 5: Non-linear PFO and PSO kinetic model plots of gliclazide adsorption for (a) MAC and (b) MMWCNT. Operating conditions: $\mathrm{pH}=5.86, \mathrm{~T}=298 \mathrm{~K}, \mathrm{~m}=0.001 \mathrm{~g}$ and $\mathrm{Co}=10 \mathrm{mg} / \mathrm{L}$. To determine the mechanisms and equilibrium conditions of the adsorption systems, the 291 Langmuir Eq.(5) (Langmuir, 1918) and Freundlich Eq. (6) (Freundlich, 1909) isotherms were 292 plotted and the parameters were calculated. Where, $\mathrm{K}_{\mathrm{L}}(\mathrm{L} / \mathrm{mg})$ is Langmuir isotherm constant, 
$\mathrm{q}_{\mathrm{m}}(\mathrm{mg} / \mathrm{g})$ is the maximum adsorption capacity, $\mathrm{K}_{\mathrm{F}}$ is Freundlich isotherm constant $(\mathrm{L} / \mathrm{g})$, and $\mathrm{n}$ is the heterogeneity factor.

$$
q_{e}=\frac{\mathrm{K}_{L} q_{m} C_{e}}{1+\mathrm{K}_{L} C_{e}}
$$

$$
q_{e}=K_{f} C_{e}^{1 / n}
$$

The nonlinear Langmuir and Freundlich isotherm plots of MAC and MMWCNT are shown in Figure 5 (a) and (b), respectively, and the isotherm model parameters are shown in Table 3. Although temperature is not a very influential parameter, the optimum temperature for MAC and MMWCNT is $298 \mathrm{~K}$ and $308 \mathrm{~K}$, respectively. When the regression coefficients were compared, higher values $\left(\mathrm{R}^{2}=0.76-0.96\right)$ were obtained for the Langmuir isotherm for both adsorbents. For this reason, it is seen that the adsorption system of gliclazide ions on carbonbased adsorbents is more compatible with the Langmuir isotherm. The maximum adsorption capacities (qm) for MAC and MMWCNT ranged from 101.66-109.20 mg/g and 28.29-71.59 $\mathrm{mg} / \mathrm{g}$, respectively. The maximum adsorption capacity for MAC was $109.20 \mathrm{mg} / \mathrm{g}$ at $298 \mathrm{~K}$, while the maximum adsorption capacity for MMWCNT was $71.59 \mathrm{mg} / \mathrm{g}$ at $318 \mathrm{~K}$. Although the temperature did not make a significant difference on the adsorption capacity, better results were obtained at lower temperatures. It is known that the adsorption process is positive when the $\mathrm{n}$ parameter takes values between 1 and 10 . The $\mathrm{n}$ values for both adsorbents vary between 1 and 2, and it can be said that gliclazide adsorption brings to a successful conclusion.

Table 3: Langmuir and Freundlich isotherm parameters for MAC and MMWCNT.

\begin{tabular}{lccccccc}
\hline \multicolumn{2}{c}{ Gliclazide Adsorption } & \multicolumn{3}{c}{ Langmuir isotherm } & \multicolumn{3}{c}{ Freundlich isotherm } \\
\cline { 3 - 8 } & $\mathbf{T}$ & $\mathbf{q}_{\mathbf{m}}(\mathrm{mg} / \mathrm{g})$ & $\mathbf{K}_{\mathbf{L}}(\mathrm{L} / \mathrm{mg})$ & $\mathbf{R}^{2}$ & $\mathbf{K}_{\mathbf{F}}(\mathrm{L} / \mathrm{mg})$ & $\mathbf{n}$ & $\mathbf{R}^{\mathbf{2}}$ \\
\hline \multirow{3}{*}{ MAC } & $298 \mathrm{~K}$ & 109.20 & 0.55 & 0.88 & 37.71 & 1.84 & 0.82 \\
& $308 \mathrm{~K}$ & 101.66 & 0.68 & 0.92 & 39.09 & 1.91 & 0.88 \\
& $318 \mathrm{~K}$ & 105.58 & 0.49 & 0.76 & 33.91 & 1.80 & 0.73 \\
\hline \multirow{3}{*}{ MMWCNT } & $298 \mathrm{~K}$ & 48.45 & 0.07 & 0.96 & 3.59 & 1.29 & 0.94 \\
& $308 \mathrm{~K}$ & 71.59 & 0.03 & 0.90 & 2.45 & 1.14 & 0.88 \\
& $318 \mathrm{~K}$ & 28.29 & 0.14 & 0.93 & 4.20 & 1.65 & 0.84 \\
\hline
\end{tabular}



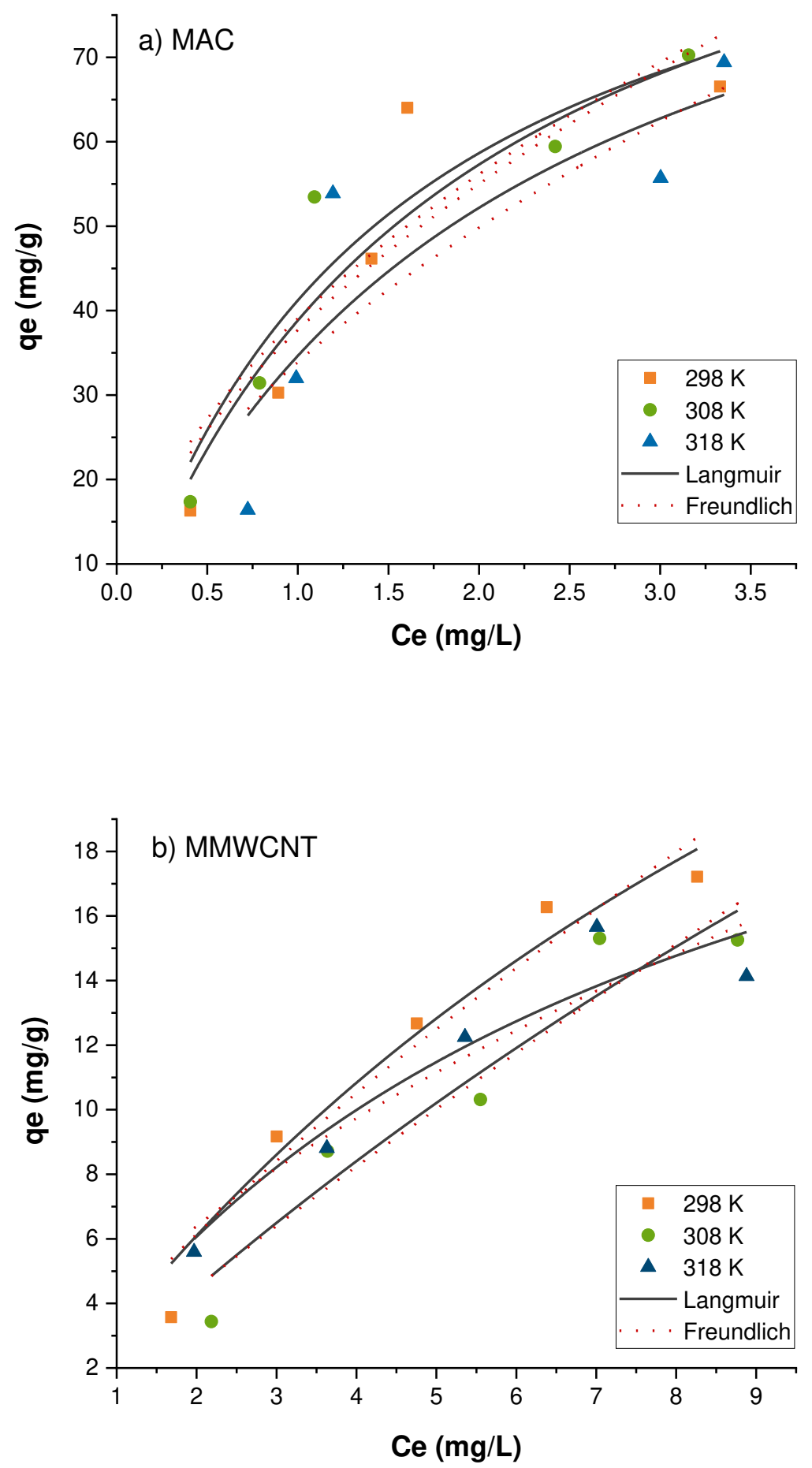

320 Figure 5: Langmuir and Freundlich adsorption isotherms for (a) MAC and (b) MMWCNT at 321 different temperatures $(298,308,318 \mathrm{~K})$. Operating conditions: $\mathrm{pH}=5.86, \mathrm{t}=120 \mathrm{~min}$ (MAC); $322180 \mathrm{~min}(\mathrm{MMWCNT}), \mathrm{m}=0.001 \mathrm{~g}$ and $\mathrm{Co}=2,4,6,8,10 \mathrm{mg} / \mathrm{L}$. 
The effect of solution $\mathrm{pH}$ (a) and foreign ion (b) on adsorption capacity is shown in figure 6 .

$325 \mathrm{pH}$ is one of the most important process variables that directly affects the adsorbate uptake by 326 the adsorbent because it can affect the extent of adsorbate ionization and the surface properties 327 of the adsorbent (Iftekhar et al., 2018). As seen in Figure 6 (a), the acidity of the environment 328 is a significant factor affecting the adsorption of gliclazide against both adsorbents. The removal 329 of gliclazide from aqueous solution decreased steadily with increasing $\mathrm{pH}$. As a result of the 330 experiments carried out at different $\mathrm{pHs}$, it can be said that the MAC and MMWCNT surfaces 331 are negatively charged with gliclazide adsorption and give better results at low $\mathrm{pH}$ values. 332 Therefore, the $\mathrm{pH}$ value of the drug solution $(\mathrm{pH}=5.86)$ was found to be suitable for adsorption 333 studies.

334 In order to estimate the adsorption capacities of adsorbents in real environment, different ion 335 effects that exist with the pollutant are examined. In this study, different concentrations of $\mathrm{NaCl}$ $336(0.001-0.1 \mathrm{~mol} / \mathrm{L})$ were used to see the effect of different ions. As seen in Figure $6(\mathrm{~b})$, the 337 presence of different concentrations of $\mathrm{NaCl}$ ion did not significantly affect the gliclazide adsorption efficiency on MAC and MMWCNT. The qe values for MAC ranged from 59.82 $\mathrm{mg} / \mathrm{g}$ to $62.59 \mathrm{mg} / \mathrm{g}$, while the MMWCNT ranged from $16.42 \mathrm{mg} / \mathrm{g}$ to $19.45 \mathrm{mg} / \mathrm{g}$.

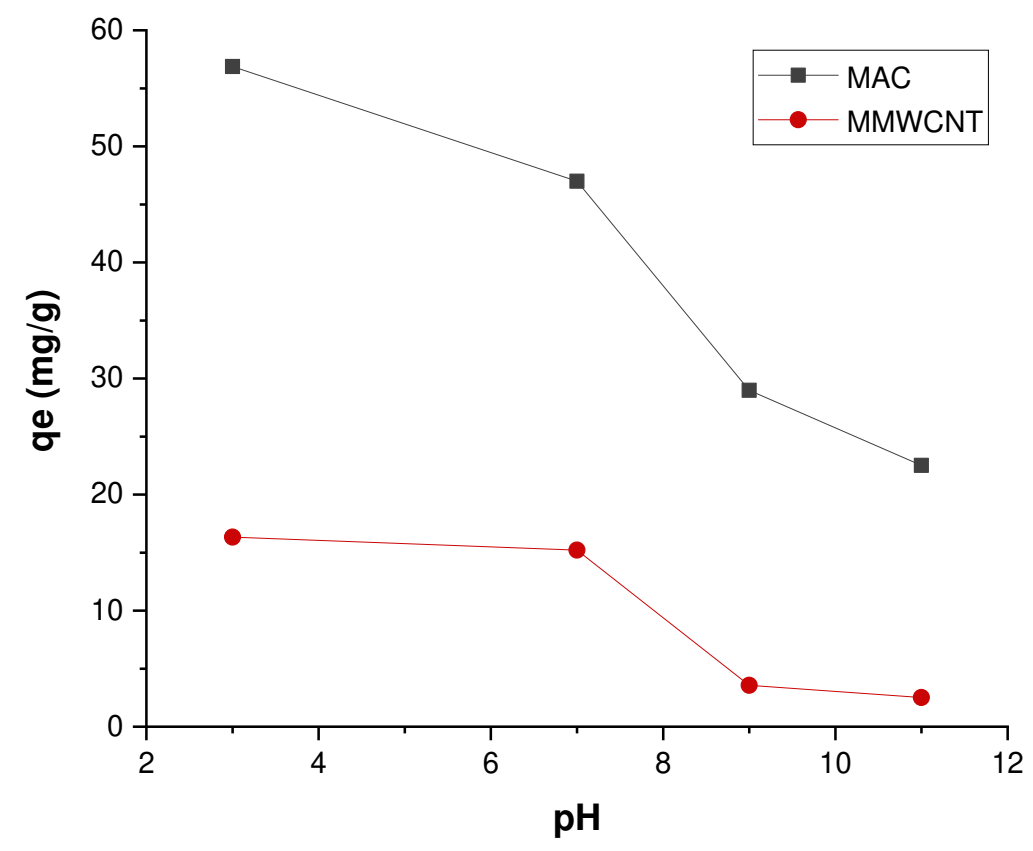




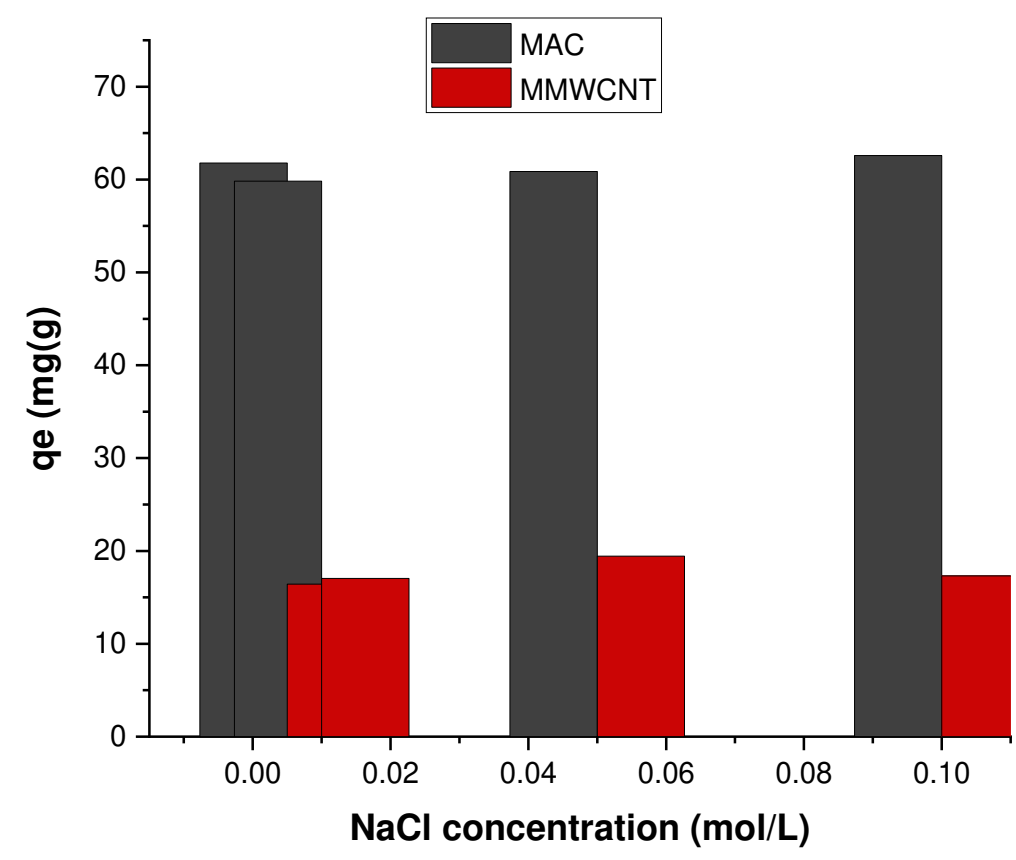

342 Figure 6: Effects of the solution $\mathrm{pH}$ (a) and presence of foreign ions (b) on adsorption capacity. 343 Operating conditions: $\mathrm{t}=120 \mathrm{~min}$ (MAC); $180 \mathrm{~min}$ (MMWCNT), $\mathrm{m}=0.001 \mathrm{~g}$ and $\mathrm{T}=298 \mathrm{~K}$.

\section{CONCLUSION}

346 MAC and MMWCNT nanoparticles used as adsorbent were magnetized using co-precipitation 347 method and characterized using FTIR, XRD and TGA techniques. For the removal of gliclazide 348 from aqueous solutions, the adsorption method was chosen and various parameters affecting 349 the adsorption system were investigated. The highest adsorption capacities were obtained for both adsorbent at $1 \mathrm{mg}$. Equilibrium times for MAC and MMWCNT were determined as 120 and 180 minutes, respectively, as a result of kinetic studies. When the kinetic model parameters of PFO and PSO were examined, gliclazide adsorption reaction kinetics gave results more compatible with PSO. According to the data of kinetic studies, MMWCNT $\left(\mathrm{k}_{2}=0.005 \mathrm{~g} / \mathrm{mg}\right.$ min) adsorbent was found to be a faster adsorbent than MAC ( $k_{2}=0.001 \mathrm{~g} / \mathrm{mg}$.min). Adsorption experiments were carried out at three several temperatures, 298, 308 and $318 \mathrm{~K}$, to define the mechanism of the hypoglycemic drug-gliclazide adsorption system. Langmuir and Freundlich equilibrium isotherm models were applied to these experimental data. The Langmuir model was more compatible with the adsorption system $\left(\mathrm{R}^{2} \geq 0.76\right)$. The maximum adsorption capacities $\left(\mathrm{q}_{\max }\right)$ for MAC and MMWCNT were calculated as $109.20 \mathrm{mg} / \mathrm{g}(\mathrm{T}=298 \mathrm{~K})$ and $71.59 \mathrm{mg} / \mathrm{g}(\mathrm{T}=308 \mathrm{~K})$, respectively. When the effects of different $\mathrm{pH}$ values were examined, 
361 it was observed that the adsorption capacity increased at low $\mathrm{pH}$ values. In other words, the $\mathrm{pH}$ 362 value $(\mathrm{pH}=5.86)$ of the drug solution was found suitable for adsorption studies. The presence 363 of different concentrations of foreign ions, $\mathrm{NaCl}$, did not significantly affect the gliclazide 364 adsorption efficiency on MAC and MMWCNT. As a result of the examination of all experiment 365 results, MAC and MMWCNT showed that there are alternative adsorbents that can be used for 366 the removal of gliclazide contaminants from aqueous solutions. But in addition, it can be said 367 that MAC adsorbent has higher adsorption capacity than MMWCNT and is more economical 368 in terms of cost in removing such a pollutant such as gliclazide.

369 
DECLARATIONS

388

389 Ethics approval and consent to participate

390 Not applicable

391 Consent for publication

392 Not applicable

393 Availability of data and materials

394 The datasets used and/or analysed during the current study are available from the corresponding 395 author on reasonable request.

396 Competing interests

397 Not applicable

398 Funding

399 Not applicable

400 Authors' contributions

401 Ferda Civan Çavuşoğlu: Conceptualization, Methodology, Validation, Writing-Review \& 402 Editing.

403 Acknowledgements

404 Not applicable

405 Authors' information

406 Ferda Civan Çavuşoğlu, $\mathrm{PhD}$

407 Assistant Professor of Chemical Engineering

408

409

Chemical Engineering Department, Faculty of Engineering-Architecture,

410 Beykent University, Istanbul, Turkey

411 E-mail: ferda.cvn@gmail.com, ferdacavusoglu@ beykent.edu.tr

412 
Alnajjar, M., Hethnawi, A., Nafie, G., Hassan, A., Vitale, G., Nassar, N.N., Silica-alumina composite as an effective adsorbent for the removal of metformin from water, J. Environ. Chem. Eng. 7 (2019) 102994.

Al-Salami H., Butt G., Tucker I., Mikov M., Influence of the semisynthetic bile acid (MKC) on the ileal permeation of gliclazide in healthy and diabetic rats, Pharmacological Reports, 60 (2008) 532-541, ISSN 1734-1140.

Baghdadi M., Ghaffari E., Aminzadeh B., Baghdadi, Removal of carbamazepine from municipal wastewater effluent using optimally synthesized magnetic activated carbon: Adsorption and sedimentation kinetic studies, 4, 3 (2016) 3309-3321.

Balasubramani K., Sivarajasekar N., Naushad M., Effective adsorption of antidiabetic pharmaceutical (metformin) from aqueous medium using graphene oxide nanoparticles: Equilibrium and statistical modelling, Journal of Molecular Liquids, 301 (2020) 112426.

Bayazit Ş.S., Magnetic multi-wall carbon nanotubes for methyl orange removal from aqueous solutions: equilibrium, kinetic and thermodynamic studies, Separation Science and Technology, 49:9 (2014) 1389-1400.

Civan Çavuşoğlu, F., Bayazit Ş.S., Secula M.S., Cagnon B., Magnetic carbon composites as regenerable and fully recoverable adsorbents: performance on the removal of antidiabetic agent metformin hydrochloride, Chemical Engineering Research and Design, 168 (2021) 443-452.

Danalığlu S.T., Bayazit Ş.S., Kuyumcu Ö.K., Salam M. A., Efficient removal of antibiotics by a novel magnetic adsorbent: Magnetic activated carbon/chitosan (MACC) nanocomposite, Journal of Molecular Liquids, 240 (2017) 589-596.

Fan C, Li K., He Y., Wang Y., Qian X, Jia J., Evaluation ofmagnetic chitosan beads for adsorption of heavymetal ions, Science of the Total Environment, 627 (2018) 1396-1403.

Freundlich, H. Kapillarchemie, eine Darstellung der Chemie der Kolloide und verwandter Gebiete. Akademische Verlagsgesellschaft, (1909).

Habibi N., Preparation of biocompatible magnetite-carboxymethyl cellulose nanocomposite: Characterization of nanocomposite by FTIR, XRD, FESEM and TEM, Spectrochimica Acta Part A: Molecular and Biomolecular Spectroscopy, 131 (2014) 55-58.

Ho, Y.S., McKay, G., Pseudo-second order model for sorption processes. Process Biochem., 34 (1999) 451-465.

Hoseininezhad-Namina M.S., Pargolghasemia P., Alimohammadib S., Radc A.S., Taqavid L., Quantum Chemical Study on the adsorption of metformin drug on the surface of pristine, Siand Al-doped (5, 5) SWCNTs, Physica E, 90 (2017) 204-213.

Huo Y., Wu H., Wang Z., Wang F., Liu Y., Feng Y., Zhao Y., Preparation of core/shell nanocomposite adsorbents based on amine polymer-modified magnetic materials for the efficient adsorption of anionic dyes, 549 (2018), 174-183.

Iftekhar, S., Ramasamy, D. L., Srivastava, V., Asif, M. B., \& Sillanpää, M., Understanding the factors affecting the adsorption of lanthanum using different adsorbents: A Critical Review. Chemosphere, 204 (2018) 413-430.

International Diabetes Federation (IDF), IDF Clinical Practice Recommendations for managing Type 2 Diabetes in Primary Care, (2017) ISBN: 978-2-930229-85-0. 
Lagergren S., Zur theorie der sogenennten adsorption geloster stoffe. Kungliga Svenska Vetenskapsakademiens Handlingar, 24 (1898) 1-39.

Langmuir, I., The adsorption of gases on plane surfaces of glass, mica and platinum. J. Am. Chem. Soc., 40 (1918) 1361-1403.

Lei W., Liu Y., Si X.,Xu J., Du W., Yang J., Zhou T., Lin J., Synthesis and magnetic properties of octahedral Fe3O4 via a one-pot hydrothermal route, Physics Letters A, (2017), 381 (4) 314318.

Liu L., Cai, W., Dang, C., Han, B., Chen, Y., Yi, R., Fan, J., Zhou, J., Wei, J., One-step vaporphase assisted hydrothermal synthesis of functionalized carbons: Effects of surface groups on their physicochemical properties and adsorption performance for $\mathrm{Cr}(\mathrm{VI})$, Appl. Surf. Sci., 528 (2020) 146984.

Liao Q., Sun J., Gao L., The adsorption of resorcinol from water using multi-walled carbon nanotubes, Colloids and Surfaces A: Physicochem. Eng. Aspects 312 (2008) 160-165.

Mrozik W.,Stefanska J., Adsorption and biodegradation of antidiabetic pharmaceuticals in soils, Chemosphere, 95 (2014) 281-288.

Niaei H.A., and Rostamizadeh, M., Adsorption of metformin from an aqueous solution by FeZSM-5 nano-adsorbent: Isotherm, kinetic and thermodynamic studies, J. Chem. Thermodyn. 142 (2020) 106003.

Oleszczuk P., Pan B., Xing, B., Adsorption and desorption of oxytetracycline and carbamazepine by multiwalled carbon nanotubes, Environ. Sci. Technol., 43 (2009) 91679173.

Palmer K.J., and Brogden R.N., Gliclazide an update of its pharmacological properties and therapeutic efficacy in non-1nsulin-dependent diabetes mellitus, Drug Evaluation, Drugs 46(I), (1993) 92-125.

Radi A., EL Ries M.A., Bekhiet G.E., Electrochemical oxidation of the hypoglycaemic drug gliclazide, Analytical Letters, 32:8 (1999)1603-1612.

Shanmugharaj A.M., Bae J.H., Lee K.Y., Noh W.H., Lee S.H., Ryu S.H., Physical and chemical characteristics of multiwalled carbon nanotubes functionalized with aminosilane and its influence on the properties of natural rubber composites, Composites Science and Technology, 67 (2007) 1813-1822.

Zhao H., Liu X., Cao Z., Zhan Y., Shi X., Yang Y., Zhou J., Xu J., Adsorption behavior and mechanism of chloramphenicols, sulfonamides, and non-antibiotic pharmaceuticals on multiwalled carbon nanotubes, Journal of Hazardous Materials, 310 (2016) 235-245.

Zhou L., Gao C., Xu W., Magnetic Dendritic Materials for Highly Efficient Adsorption of Dyes and Drugs, ACS Appl. Mater. Interfaces, 2, 5, (2010) 1483-1491.

Zhu S., Liu Y., Liu S., Zeng G., Jiang L., Tan X., Zhou L., Zeng W., Li T., Yang C., Adsorption of emerging contaminant metformin using graphene oxide, Chemosphere 179 (2017) 20-28. 


\section{Supplementary Files}

This is a list of supplementary files associated with this preprint. Click to download.

- GraphicalAbstract.pdf 